\section{Lichenoid drug eruption due to eprosartan/hydrochlorothiacide}

\author{
Ricardo Ruiz-Villaverde, \\ Manuel Galan-Gutierrez \\ FEA Dermatología, Complejo \\ Hospitalario de Jaen, Jaen, Spain
}

\begin{abstract}
We report a case of a 66-year-old male who developed an itchy eruption while taking an antihypertonic drug containing eprosartan and hydrochlorothiacide after sun exposure. The lesions resembled a lichenoid appearance that was confirmed by the histological study. There are few reports in the literature of lichenoid reactions to these compounds, so we review the characteristics of themselves as a potencial cause of drug eruptions.
\end{abstract}

\section{Case Report}

A 66-year-old male attended to our outpatients clinic presenting a 2 months history of an itchy skin eruption. It has not been controlled with topical steroids and antihistamines ruled by his general practitioner. No personal or family history of atopy or other allergic diseases were referred. He had a history of high blood preasure that was under control with eprosartan $600 \mathrm{mg} /$ hydrochlorotyacide $12.50 \mathrm{mg}$ for the last 7 months.

On skin examination we could appreciate multiple red papules and plaques on the chest, both forearms (the site where the eruption begun regarding the patient's comments), back and thighs (Figures 1,2). Some papules had a fine pityriasiform scaling. There was no commitment of the cephalic pole. Wickam's striae were not seen. Dermographism was normal. There were no lesions of lichen planus in the oral cavity.

Blood count test, general biochemistry, ANA, ESR (erythrocyte sedimentation rate) and hepatic viral serology were ordered and showed normal results. The histological examination revealed epidermal hyperplasia with orthokeratosis, focal hypergranulosis, hydropic degeneration of the basement membrane zone and lichenoid-like lymphocytic infiltrate in the papillary dermis (Figure 3 ).

Patch test according the Spanish Contact Dermatitis Group (True test ${ }^{\circledR}$ ) were performed and also the antihypertensive drug (Teveten Plus ${ }^{\circledR}$ ). Single substances (eprosartan and hydroclorothiacide) were also tested. We found only positivity in the patch of the compound drug. Seven control subjects were tested with the same compound showed no reaction. Phototesting was not performed, as this was only available at another center out from our region.

Regarding the clinical, histological and patch test results, lichenoid drug eruption due to the intake of eprosartan/hydroclorothiacide was made. We proceed to discontinuate the treatment with the antihypertensive drug and we administrated $1 \mathrm{mg} / \mathrm{kg} / \mathrm{d}$ of prednisone. In two weeks the eruption healed, so we started to get down cortichosteroids. Dark-brown macular hyperpigmentation of some of the skin lesions were presented.

Eprosartan is an angiotensin II receptor antagonist (angiotensin II receptor blocker) used in the treatment of hypertension. In large, randomized trials, eprosartan (with or without hydrochlorothiazide [HCTZ]) demonstrated superior antihypertensive efficacy to that of placebo, but the use of eprosartan in combination with HCTZ tends to reverse the potassium loss associated with thiazide diuretics. The incidence of cutaneous adverse events is quite low. ${ }^{1}$

On the other hand, the potential of the thiazide group to cause cutaneous reactions as eczematous reactions, erythema multiforme and lichenoid changes have been widely reported. ${ }^{2}$

The use of these two drugs together is relatively recent and therefore the number of reported skin reactions is also very low. There has just been one case reported of lichenoid drug reaction with the compound of irbesartan and hydroclorothiacide. Pfab et al. ${ }^{2}$ explained that the negative patch test to the single substances could be interpreted as a compound allergy. The combination of these two substances may produce a neoantigenic effect.

Lichenoid drug eruptions are commonly associated with gold, antimalarials, thiazides and phenotiazines. We should note that although the morphology of lichenoid eruptions is reminiscent of lichen planus, the following differences may occur: ${ }^{3}$ i) beginning as hyperpigmented lesions or eczematous lesions; ii) do not present Wickham striae on

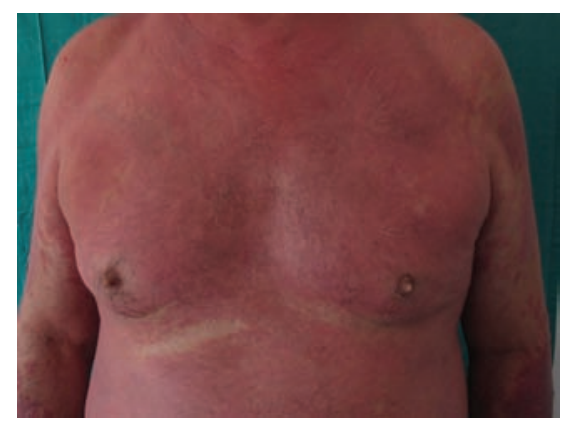

Figure 1. Confluent eruption of erythemato-violaceus plaques on the chest.
Correspondence: Ricardo Ruiz Villaverde, Dermatology Unit, Complejo Hospitalario de Jaen Avda. Ejército Español s.n. 23007 Jaen, Spain.

Tel. +34.953 .008 .000$

E-mail: ismenios@hotmail.com

Key words: lichenoid eruption eprosartan hydrochlorothiacide.

Received for publication: 21 August 2011. Accepted for publication: 24 August 2011.

This work is licensed under a Creative Commons Attribution NonCommercial 3.0 License (CC BYNC 3.0).

(C) Copyright R. Ruiz-Villaverde and M. GalanGutierrez, 2011

Licensee PAGEPress, Italy

Dermatology Reports 2011; 3:e31

doi:10.4081/dr.2011.e31

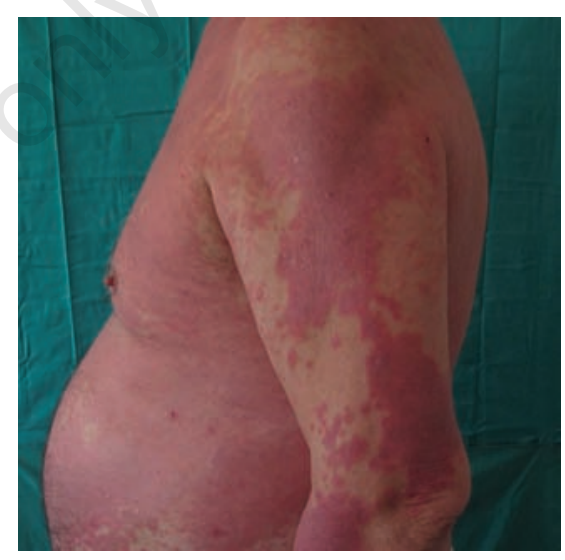

Figure 2. Cutaneous affection of the forearm.

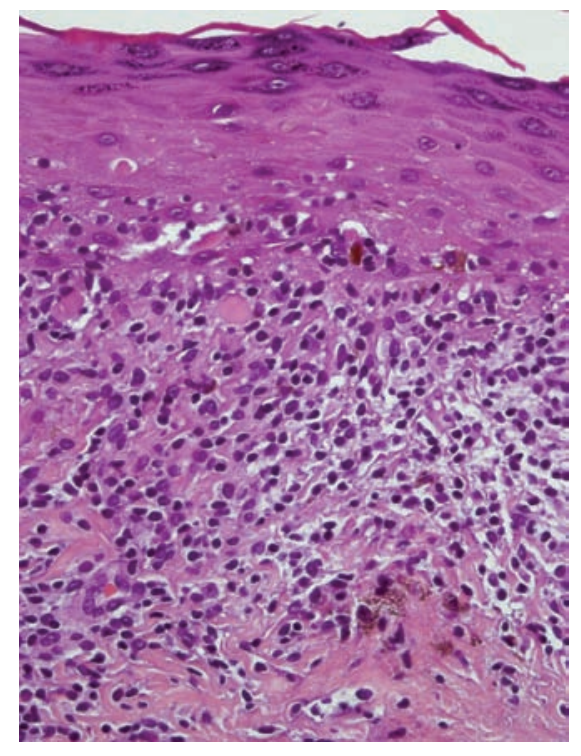

Figure 3. Epidermal hyperplasia with hyperkeratotic foci, lichenoid dermatitis and lichenoid-like lymphocytic infiltrate in the papillary dermis. 
their surface; iii) do not affect mucous membranes not the nails; iv) sometimes have a typical distribution in photoexposed areas and v) Intense presence of eosinophile in the inflammatory infiltrate.

For severe generalized lichen planus eruptions, systemic corctichosteroids are effective. In prolonged treatments other therapeutical options could offer good results as sulfasalazine,${ }^{4}$ methotrexate,${ }^{5}$ azathioprine, ${ }^{6}$ interferon alfa $2 b,{ }^{7}$ alefacept, ${ }^{8}$ thalidomide ${ }^{9}$ or enoxaparine..$^{10}$ It is really important to choose the most adequate treatment depending on the severity and the basal status of the patient at time of diagnosis.

\section{References}

1. Plosker GL. Eprosartan: a review of its use in hypertension. Drugs 2009;69:2477-99.

2. Pfab F, Athanasiadis GI, Kollmar A, et al. Lichenoid drug eruption due to an antihypertonic drug containing irbesartan and hydrochlorothiazide. Allergy 2006;61:786-7.

3. Ruiz Villaverde R, Blasco Melguizo J, et al. Lichen planus-like eruption due to enalapril. J Eur Acad Dermatol Venereol 2003;17:612-4.

4. Omidian M, Ayoobi A, Mapar MA, et al. Efficacy of sulfasalazine in the treatment of generalized lichen planus: randomized double-blinded clinical trial on 52 patients. J Eur Acad Dermatol Venereol 2010;24: 1051-4.

5. Turan H, Baskan EB, Tunali S, et al. Methotrexate for the treatment of generalized lichen planus. J Am Acad Dermatol 2009; 60:164-6.

6. Kaushal K, Verma CS, Sirka S, Khaitan K. Generalized severe lichen planus treated with azathiprine. Acta Derm Venereol 1999;79:493.

7. Hildebrand A, Kolde G, Luger TA, Scharz T. Successful treatment of generalized lichen planus with recombinant interferon alfa2b. J Am Acad Dermatol 1995;33:880-3.

8. Fivenson DP, Mathes B. Treatment of generalized lichen planus with alefacept. Arch Dermatol 2006;142:151-2.

9. Maender JL, Krishnan RS, Angel TA, Hsu S. Complete resolution of generalized lichen planus after treatment with thalidomide. J Drugs Dermatol 2005;4:86-8.

10. Hodak E, Yosipovitch G, David M, et al. Low-dose low-molecular-weight heparin (enoxaparin) is beneficial in lichen planus: a preliminary report. J Am Acad Dermatol 1998;38:564-8. 